\title{
Design and Analysis of Class-E Power Amplifier for Wired \& Wireless Systems
}

\author{
Ms. Sweta Minj \\ Research Scholar, Shri Rawatpura Sarkar Group of Institutions, Raipur, India \\ swetaminj@rsgi.edu.in
}

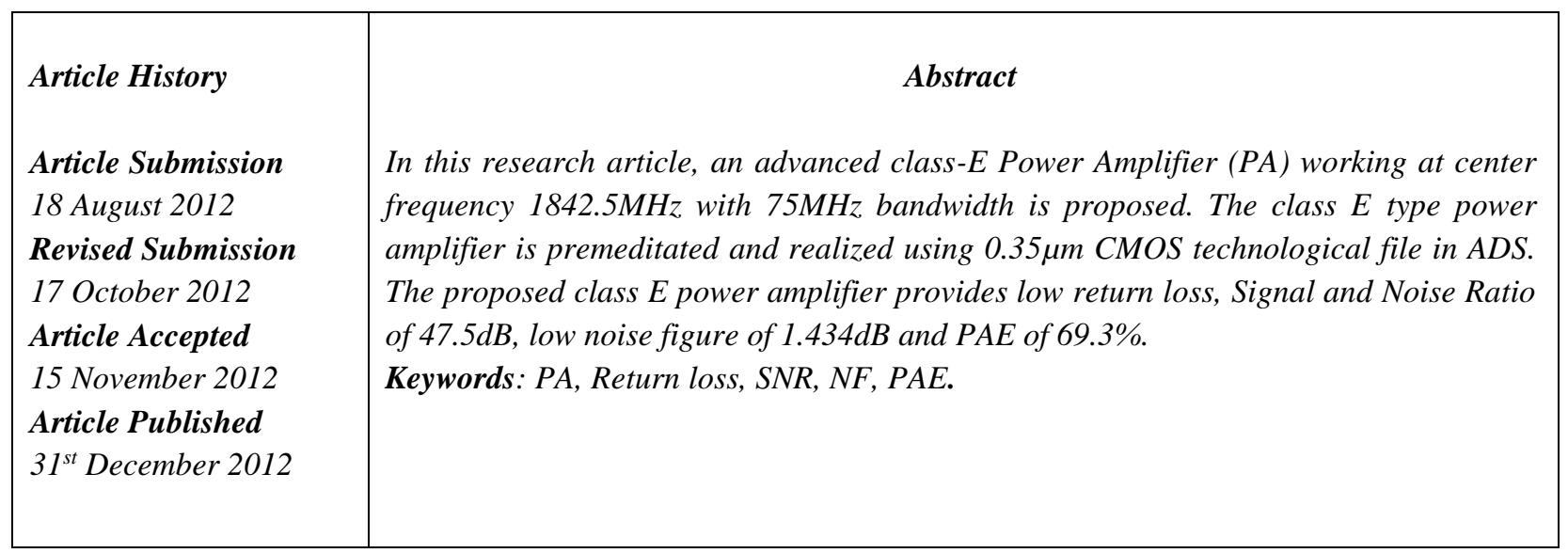

\section{Introduction}

Power amplifiers are usually employed to translate radio frequency signal with low power into a high amplitude signal which is opted to drive the antennas in the receivers and transmitter. Modern day portable systems employs power amplifier as it act as the heart of these systems. Power amplifiers (PAs) also play a significant role in the transmitter leading to superior amplification of baseband and narrowband signals. Figure 1 depicts the block diagram of transmitter.

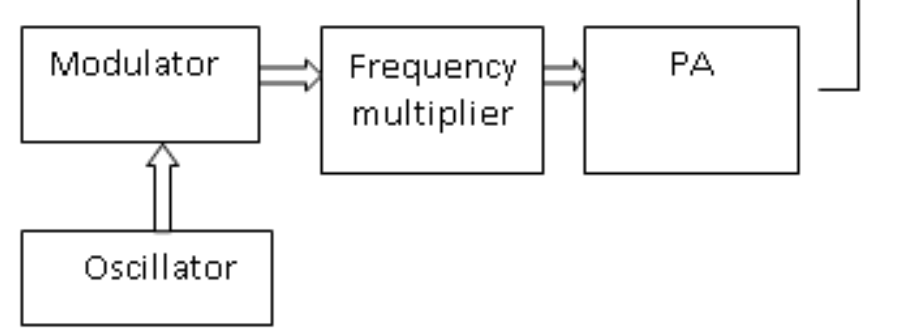

Fig 1. Sketch of a transmitter

Power amplifier selection depends on efficiency and linearity of the particular amplifier. The various classification of power amplifiers are given below:

ISSN: 2250-0839

(C) IJNPME 2012 
- Efficient Class A PA

- Efficient Class B PA

- Efficient Class AB PA

- Efficient Class C PA

- Efficient Class D PA

- Efficient Class E PA

- Efficient Class F PA

All the above power amplifiers differs in conduction input angle, frequency variations, biasing and harmonics condition. The increase in linearity of the PA is inversely relative to its efficiency. In other words, increase in linearity drastically affects the efficiency of the PA. Class E-PA is preferred because linearity of the class E - PA is directly relative to its efficiency. Other reasons include: size parameter, easy design features and less weight.

\section{Proposed Class-E Power Amplifier}

All the power amplifiers uses active device for power amplification. Power amplifier's high efficiency is due to the presence of active devices comprising of various transistors. Initially Class-E power amplifiers included BJT as its switching device [1].

Due to power dissipation, output undergone major loss of power. Therefore, power dissipation is minimized in power amplifiers to work at high frequencies [2]-[3]. Nathan Sokal et al. (1970) were the first to explore the design concepts of class-E PA.

Nathan et al. (1970) also provided the design equations of class E PA that act as a benchmark for future research work in class E power amplifiers. They also identified matching networks play a vital role in reduction of power intake by amplifiers [4].

The matching network of class $\mathrm{E}$ amplifier has a sophisticated design with low loss. The efficiency of class $\mathrm{E}$ amplifier is relatively higher than class $\mathrm{B}$ and class $\mathrm{C}$ amplifiers [5]. The vital conditions to get better the competence of the amplifier is as follows:

1. The peak point of I \& V waveforms during full scale operation must be greater than time. When switch is on, it should not lead to any voltage drop and the current flows through the circuit [6].

2. On contrast, a small amount of voltage is induced during switch off condition leading to blockage of any current flow.

The design equations used for finding the values of circuit elements of the class E-PA are shown below:

$$
\begin{gathered}
R_{L}=\frac{\left(V_{D D}-V_{D S(\text { Sat })}\right)^{2}}{P_{a}}\left(\frac{2}{\frac{\pi^{2}}{4}+1}\right)=0.577 \frac{\left(V_{D D}-V_{D S(\text { Sat })}\right)^{2}}{P_{a}} \\
L=\frac{Q_{L} R_{L}}{2 \pi f}
\end{gathered}
$$




$$
\begin{gathered}
C_{1}=\frac{1}{2 \pi f R_{L}\left(\frac{\pi^{2}}{4}+1\right)\left(\frac{\pi}{2}\right)} \\
C_{2}=C_{1}\left(\frac{5.447}{Q_{L}}\right)\left(1+\frac{1.42}{Q_{L}-2.08}\right)
\end{gathered}
$$

The schematic sketch of Circuit of class-E PA is shown in figure 2.

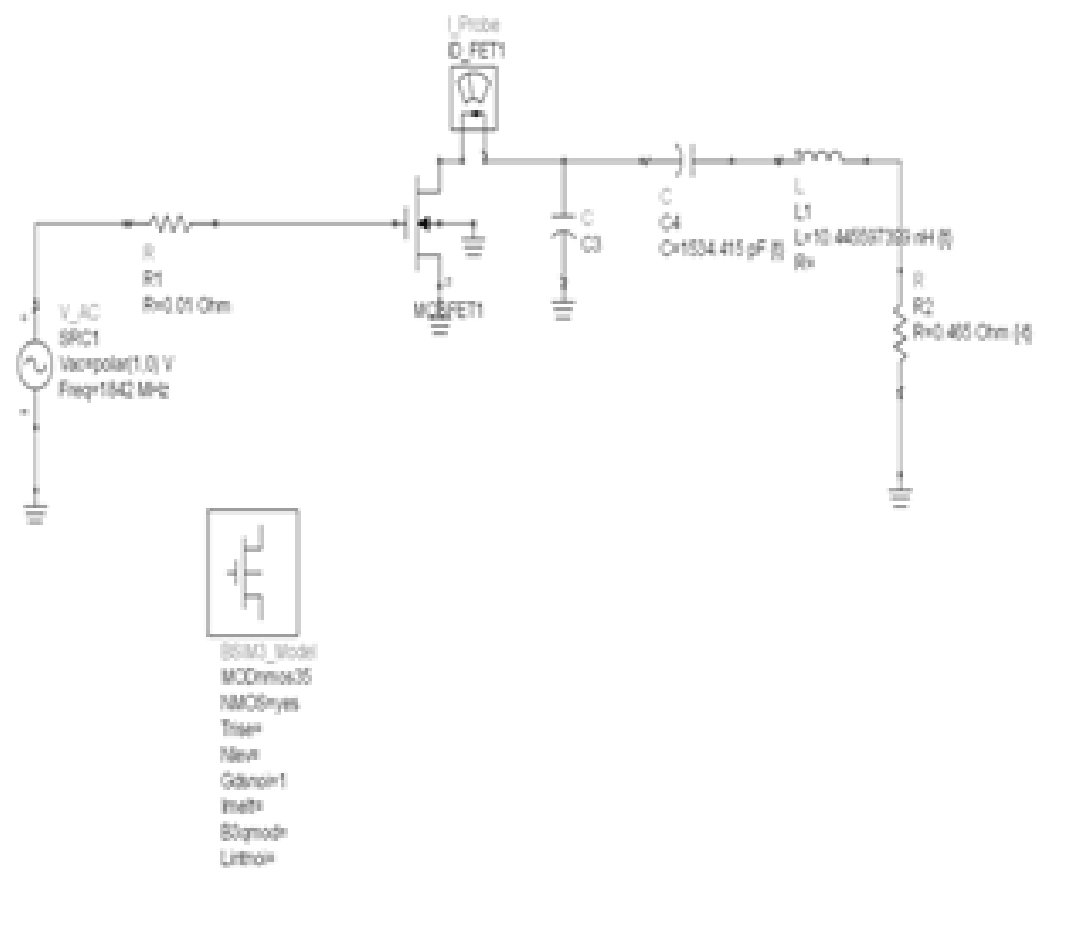

Fig 2.Schematic diagram of Class E PA

The design specifications for proposed class E PA include center frequency which tuned to $1842.5 \mathrm{MHz}$. Bandwidth of the proposed circuit is limited to $75 \mathrm{MHz}$. The design specifications of proposed class E PA with specified frequency in the specified band is given in table 1.

Table 1. Design Specifications of the Proposed Class E Pa

\begin{tabular}{|l|l|}
\hline Parameters & Power amplifier \\
\hline Center frequency & $1842.5 \mathrm{MHz}$ \\
\hline Bandwidth & $75 \mathrm{MHz}$ \\
\hline Technology & $0.35 \mu \mathrm{m} \mathrm{CMOS}$ \\
\hline
\end{tabular}

ISSN: 2250-0839 
The values of components used in the circuit of power amplifier is given in Table II.

Table 2. Values of Components in Class-E Power Amplifier

\begin{tabular}{|l|l|}
\hline Components & Values used in the circuit \\
\hline Length & $0.68 \mu \mathrm{m}$ \\
\hline Width & $843 \mu \mathrm{m}$ \\
\hline $\mathrm{C} 3$ & $0.466982 \mathrm{pF}$ \\
\hline $\mathrm{C} 4$ & $1499.415 \mathrm{pF}$ \\
\hline $\mathrm{R} 1$ & $0.0001 \Omega$ \\
\hline $\mathrm{R}_{\mathrm{L}}$ & $100 \Omega$ \\
\hline
\end{tabular}

\section{Simulation of the Proposed Class E Power Amplifier}

Various PSPICE simulations are performed that includes transient analysis, S-matrix parameter analysis, and AC \& DC analysis. Transient analysis predicts whether VI product is high or low. Transient response for the power amplifier operating at $1842.5 \mathrm{MHz}$ is shown in fig.3

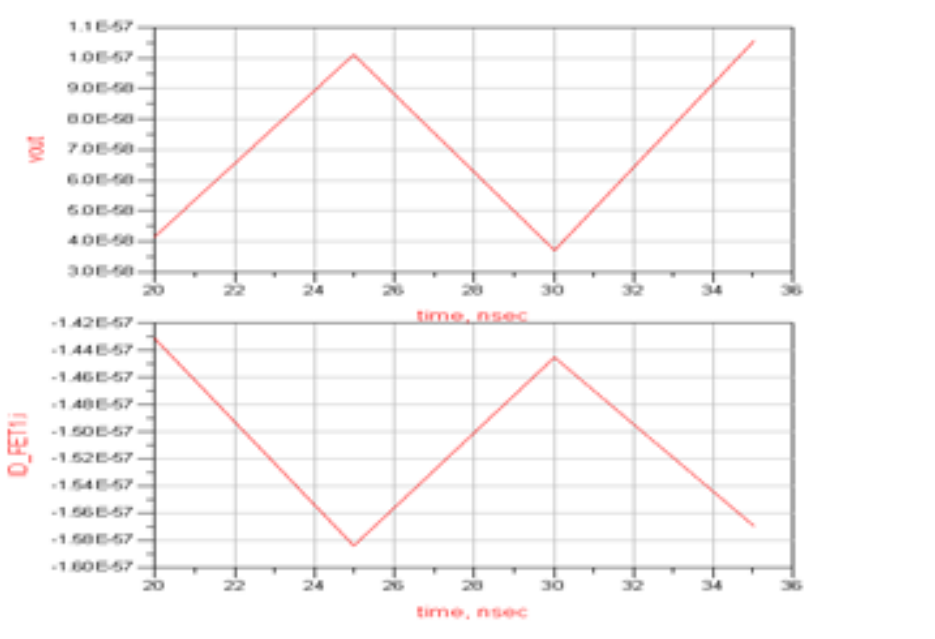

Fig.3 momentary analysis of power amplifier

Figure 3 shows that product $\mathrm{V} x \mathrm{I}$ is minimum in the proposed power amplifier. S-parameter simulation comprising of forward voltage gain curve $\left(S_{21}\right)$, return loss $\left(S_{11}\right)$. The $S$-parameter simulation results of proposed class-E PA is shown in fig.4. 


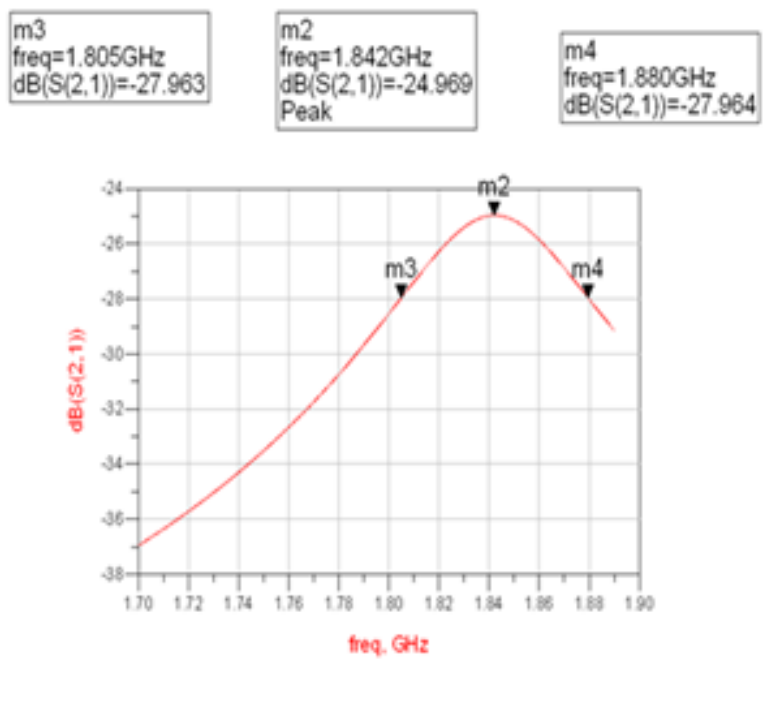

$\mathrm{S}_{21}$

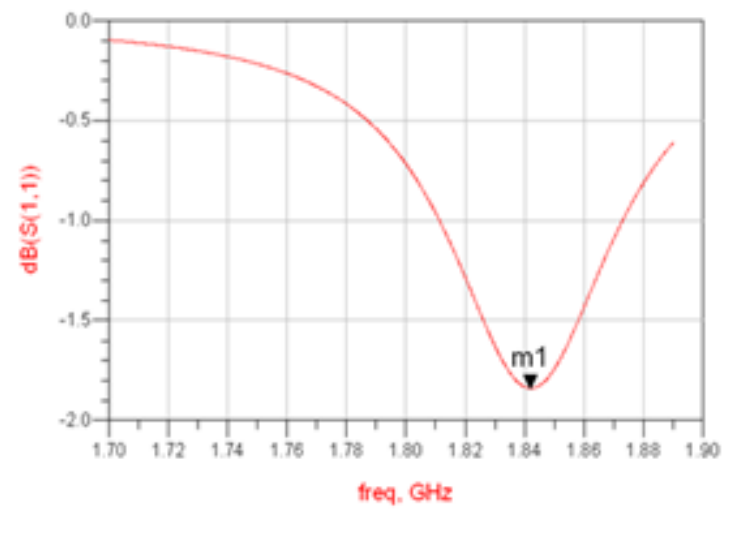

$\mathrm{S}_{11}$

Fig.4 S-Parameter simulation of Class-E PA at $1842.5 \mathrm{MHz}$

Rollette stability factor $\mathrm{k}>1$ and stability measure $\Delta<1$ indicates the system is unconditionally stable. Simulation analysis comprising of Stability measure $\Delta$ and Stability factor $\mathrm{k}$ are shown in figure 5 .

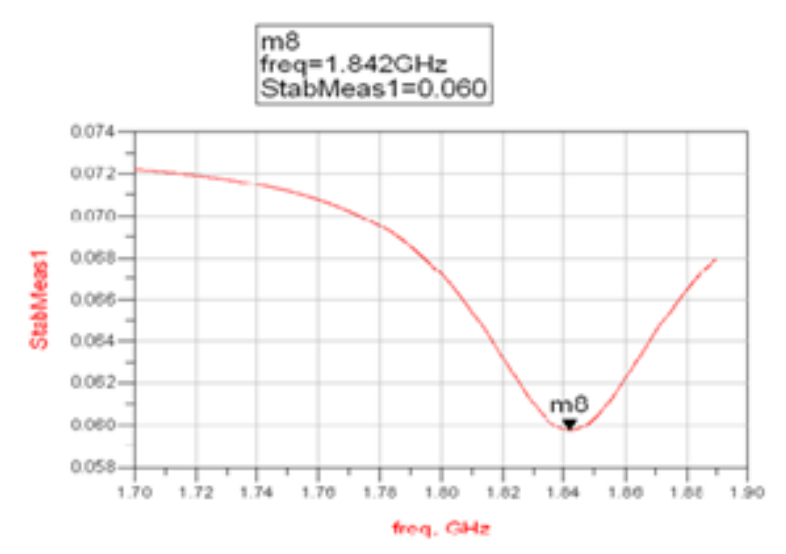

(a) Stability measure $\Delta$

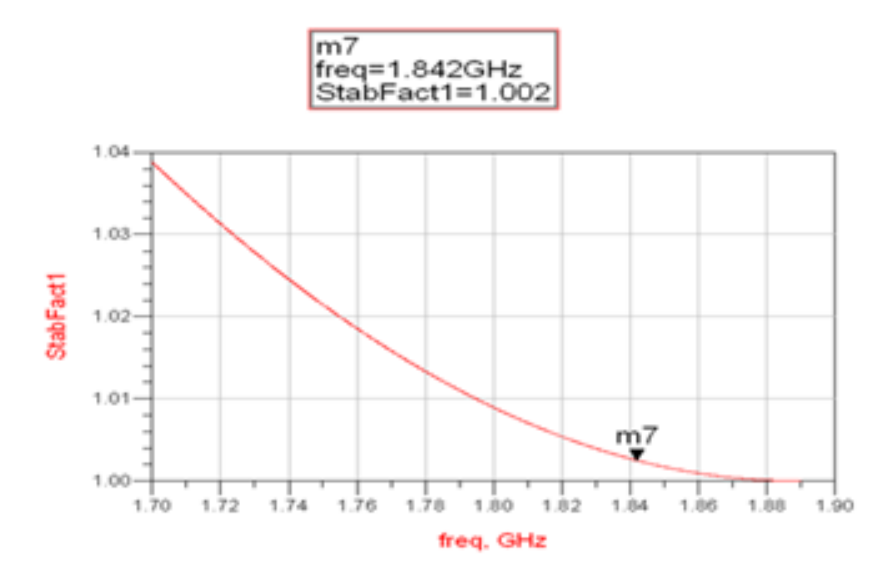

(b)Stability factor $\mathrm{k}$

Fig.5 Rollette stability factors 
AC Simulation is carried out to discover the NF \& SNR. Noise figure is calculated using Eq.6 as:

$$
\begin{aligned}
& \text { Noise factor }(F)=\frac{S N R_{i}}{S N R_{o}} \\
& \operatorname{NOISE~FIGURE~}(N F)=10 * \log (F)
\end{aligned}
$$

Simulation analysis comprising of noise figure (NF) and signal / noise ratio (SNR) are shown in figure 6.

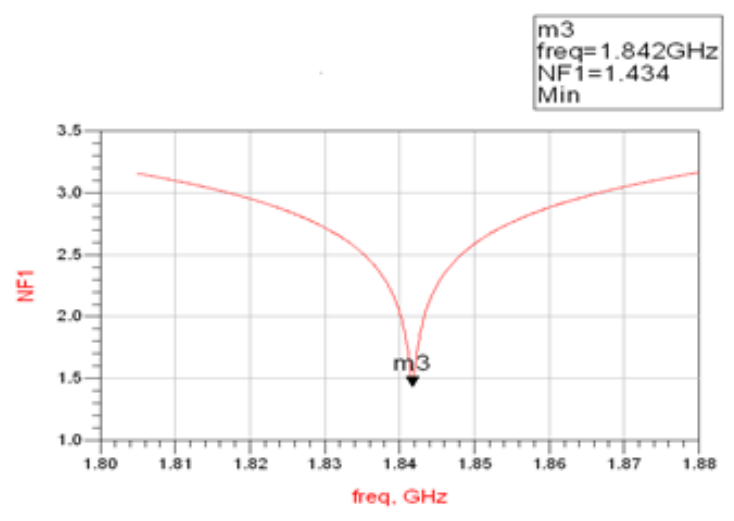

(a) NF

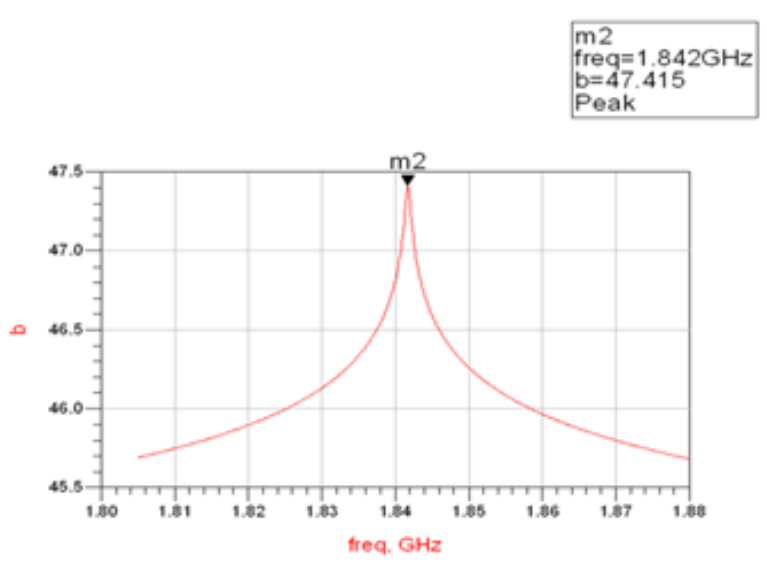

(b)SNR

Fig.6. Noise figure and SNR of power amplifier

Table 3. Iiummary of Results

\begin{tabular}{|c|c|}
\hline PARAMETERS & RESULTS \\
\hline Stability factor & $\Delta=0.060<1, \mathrm{k}=1.002>1$ \\
\hline Noise figure & $1.434 \mathrm{~dB}$ \\
\hline SNR & $47.415 \mathrm{~dB}$ \\
\hline PAE & $69.30 \%$ \\
\hline
\end{tabular}

\section{Conclusion}

Class-E Power amplifier for center frequency $1842.5 \mathrm{MHz}$ is designed and various performance parameters are analyzed. The proposed class E power amplifier gives a PAE of $69.30 \%$ which is higher than the power amplifiers in literature with PAE $64 \%$. The NF of proposed amplifier at $1.434 \mathrm{~dB}$ for $1842.5 \mathrm{MHz}$ is obtained. The output of ClassE PA is non-linear. As future work the linearity has to be improved by appropriate linearization techniques.

\section{References}

[1] N. O. Sokal and A. D. Sokal, "Class E a new classof high efficiency tuned single-ended switching power amplifiers”, IEEE J. Soild-State Circuits, vol. SC-10, No. 3, pp. 168-176, June 1975.

[2] Zia Nadir,Farid Touati, "Design of high frequency switching mode Power amplifier for RF and 
microwave",FYP,SQU May 2008

[3] M. Dhawyani, Q. Mahrooqi, F. Rahbi, A.Kalbani, F. Touati, Z. Nadir, "Improvement in the efficiency of class-E power amplifier for RF",IEEE-Multi conference on systems, signals and Devices, SSD-2008, Philadelphia University,Amman, Jordan, July 20-23, 2008.

[4] N.O.Sokal,"Class-E RF power amplifiers", WA1HQC of design automation, Inc ARRL Technical Advisor,Jan/Feb2001

[5] Zia Nadir,Farid Touati,'High Efficiency Switching Mode Class-E power amplifier Design Improvements for RF”,UPM Serdang,Malaysia,Nov 2009

[6] Sampath P and Gunavathi K,"Class-E power amplifier and its linearization using analog predistortion", Indian journal of Engineering and material sciences Vol.19, April 2012.

[7] Tan, Jun \& Heng, Chun-Huat \& Lian, Yong. (2012). Design of Efficient Class-E Power Amplifiers for Short-Distance Communications. Circuits and Systems I: Regular Papers, IEEE Transactions on. 59. 22102220. 10.1109/TCSI.2012.2188951.

[8] M. Acar, A. J. Annema, and B. Nauta, “Analytical design equations forclass-E power amplifiers,” IEEE Trans. Circuits Syst. I, Reg. Papers,vol. 54, no. 12, pp. 2706-2717, Dec. 2007

[9] S. Sivakumar and A. Eroglu, "Analysis of class-E based RF power am-plifiers using harmonic modeling," IEEE Trans. Circuits Syst. I, Reg.Papers, vol. 57, no. 1, pp. 299-311, Jan. 2010 